Infect Dis Obstet Gynecol 2003;11:131-133

\title{
Vulvovaginal trichosporonosis
}

\author{
Paul Makela ${ }^{1}$, Debbie Leaman ${ }^{2}$ and Jack D. Sobel ${ }^{2}$ \\ ${ }^{1}$ Department of Obstetrics and Gynecology and \\ ${ }^{2}$ Division of Infectious Disease, Wayne State University School of Medicine, Detroit, MI
}

\begin{abstract}
Objective: Isolation of Trichosporon species from vaginal secretions is a rare event, and no data are available on its pathogenic role. A case series is presented to determine the pathogenic role of Trichosporon species in vulvovaginal infections.

Methods: We performed a retrospective chart review of patients seen in the W.S.U. Vaginitis Clinic in order to identify patients from whom Trichosporon species were isolated.

Results: Between 1986 and 200 I, a total of I 3 patients had a total of I 8 positive vaginal cultures for Trichosporon species. All 18 vaginal isolates were $T$. inkin. In general, positive vaginal cultures were accompanied by low yeast colony counts. Four out of 18 positive $T$. inkin cultures were obtained from visits by asymptomatic patients. Of the remaining 14 positive $T$. inkin cultures from patients with symptoms, nine out of 14 cultures had other diagnoses (Candida albicans, six cases; bacterial vaginosis, two cases; Trichomonas, one case). Five positive $T$. inkin cultures were obtained from visits at which patients had symptoms and no associated diagnosis. In only one of the five episodes could we establish a clear pathogenic role for Trichosporon. In this case the patient was treated with boric acid and had resolution of symptoms and a negative culture at follow-up. In-vitro susceptibility tests revealed that $T$. inkin was resistant to flucytosine and susceptible to all topical and oral azoles.

Conclusions: $T$. inkin is occasionally found in vulvovaginal cultures and is usually a non-pathogen. Transient colonization tended to occur in women, usually of African-American origin, with major perturbations in vaginal flora (bacterial vaginosis and trichomoniasis) and increased $\mathrm{pH}$. Pathogenic consequences of Trichosporon colonization appear to be rare.
\end{abstract}

Key words: TRICHOSPORON INKIN; VAGINITIS; BACTERIAL VAGINOSIS; VULVOVAGINAL CANDIDIASIS

Trichosporon is a genus of basidiomycetous yeasts. Trichosporon species are widely distributed, being found in soil, stagnant and fresh water and animal excrement ${ }^{1}$. They may also be part of the normal human skin and respiratory tract flora ${ }^{1}$. In 1992 , the genus Trichosporon was revised by Gueho et al. ${ }^{2}$. Six human pathogenic species of Trichosporon have been described, namely $T$. asahii, $T$. asteroids, T. cutaneum, T. inkin, T. mucoides and T. ovoids ${ }^{3}$. A well-known manifestation of Trichosporon infection is white piedra, with the formation of hard nodules on hair shafts ${ }^{4}$. Trichosporon species also commonly cause cutaneous infections ${ }^{5}$. Increasingly, Trichosporon species may be involved in invasive local or disseminated infections in immunocompromised patients, often with a fulminant course and fatal outcome ${ }^{1}$.

Specifically, T. inkin is known to be involved in the occurrence of white piedra in the genital area ${ }^{4}$. Other manifestations of $T$. inkin infection that have been reported include prosthetic mitral valve endocarditis ${ }^{6}$, peritonitis in a peritoneal dialysis patient $^{7}$, and a pulmonary abscess in a child with chronic granulomatous disease ${ }^{8}$. Isolation of

Correspondence to: Paul Makela, MD, 4707 St Antoine, Detroit, MI 48201, USA. Email: pmakela@med.wayne.edu 
Trichosporon species from the vaginal canal is a rare event, and no data are available on its pathogenic role.

\section{SUBJECTS AND METHODS}

\section{Study population}

The Vaginitis Clinic laboratory records were reviewed for all cultures growing Trichosporon species from 1986 to 2002 . A total of 13 patients had positive vaginal cultures for Trichosporon species.

\section{Laboratory methods}

All vaginal specimens of patients who are seen in the clinic, whether those individuals are symptomatic or not, are cultured for fungi. Specimens were placed on plates with media selective for Candida growth (Sabouraud's dextrose agar). Suspected mixed cultures, as determined by colony type and macroscopic characteristics, were placed on plates with media showing species-specific colony color change (Chromagar, CHROMagar, Paris, France). Trichosporon species were identified by carbohydrate assimilation tests (API-20C Aux). In-vitro susceptibility tests were performed using the National Committee for Clinical Laboratory Standards M27-A method ${ }^{9}$.

\section{RESULTS}

A total of 13 patients who were seen at the Vaginitis Clinic between 1986 and 2002 had a total of 18 positive cultures for Trichosporon species. Notably, 11 out of 13 patients (85\%) were of African-American origin. The 13 patients had a mean age of 32 years. One patient had a history of diabetes mellitus. All 18 vaginal isolates were identified as $T$. inkin. In general, positive Trichosporon vaginal cultures were accompanied by low yeast colony counts. In addition to two women with bacterial vaginosis and one with trichomoniasis, six positive $T$. inkin cultures were obtained from women with an elevated $\mathrm{pH}$ $(\mathrm{pH}>4.5)$. Routine saline and $10 \%$ potassium hydroxide microscopy were rarely positive for yeast and could not determine a pathogenic role for T. inkin. Four out of 18 positive T. inkin cultures were obtained from visits by three asymptomatic patients who were seen on routine follow-up examinations. Of the remaining 14 positive $T$. inkin cultures obtained from patients with symptoms, nine out of 14 cultures had other diagnostic entities or pathogens, namely Candida albicans $(n=6)$, bacterial vaginosis $(n=2)$ and trichomoniasis $(n=1)$. Five positive $T$. inkin cultures were obtained from visits at which patients had symptoms and no associated diagnosis. Two out of five positive T. inkin cultures were obtained from patients who had no follow-up. One out of five positive $T$. inkin cultures was obtained from a patient who received no treatment and had a negative culture at the next visit, and one out of five positive $T$. inkin cultures was obtained from a patient who was not treated until a follow-up visit, which was culture positive for $T$. inkin and C. albicans. The patient showed resolution of symptoms and had a negative culture after treatment with fluconazole. Only one out of five positive $T$. inkin cultures was obtained from a patient who had vulvovaginal symptoms and no other diagnostic etiology apart from $T$. inkin. This patient showed resolution of symptoms and negative cultures with topical boric acid therapy, $600 \mathrm{mg}$ daily for 14 days. This was the only patient in whom we could establish a probable pathogenic role for Trichosporon. In-vitro susceptibility tests revealed that $T$. inkin was resistant to flucytosine and susceptible to all topical and oral azoles. Testing of the susceptibility of Trichosporon species to azoles revealed the following minimal inhibitory concentration (MIC) ranges: fluconazole, $1-4 \mathrm{mg} / \mathrm{ml}$; intraconazole, $\quad 0.125-0.5 \mathrm{mg} / \mathrm{ml}$; voriconazole, $\quad 0.3-0.125 \mathrm{mg} / \mathrm{ml}$; miconazole, $0.03-0.5 \mathrm{mg} / \mathrm{ml}$; clotrimazole, $0.3-0.125 \mathrm{mg} / \mathrm{ml}$; ketoconazole, $0.06-0.25 \mathrm{mg} / \mathrm{ml}$.

\section{DISCUSSION}

Vulvovaginal candidiasis (VVC) is the second most common cause of vaginal infections after bacterial vaginosis in the USA. If only US studies are considered, $80-95 \%$ of VVC is caused by Candida albicans and the rest is caused by a variety of non-albicans Candida species ${ }^{10}$. Less than $1 \%$ of vaginal fungal infections are caused by non-Candida species ${ }^{11}$. Unusual fungi that have

I32 • INFECTIOUS DISEASES IN OBSTETRICS AND GYNECOLOGY 
been reported include Saccharomyces cervisiae ${ }^{12}$ and Zygomycetes $^{13}$, which were reported in healthy non-immunocompromised patients. Although it is known that Trichosporon species infrequently cause invasive infections in humans, there is no report in the literature of vaginitis caused by any species of Trichosporon. Based on our analysis, T. inkin is occasionally found in vulvovaginal cultures and is usually a non-pathogen. Trichosporon species (e.g. T. asahii) commonly cause cutaneous and invasive systemic disease, whereas $T$. inkin appears to be selectively and uniquely isolated from genital specimens ${ }^{5,14}$. In only one out of 13 patients could a likely pathogenic role be established for $T$. inkin. In this patient, elimination of vulvovaginal symptoms corresponded to previously positive vaginal cultures for $T$. inkin becoming negative following antimycotic therapy. Transient colonization tended to occur predominantly in African-American women with major perturbations of the vaginal flora (bacterial vaginosis and trichomoniasis) with increased vaginal $\mathrm{pH}$. Pathogenic consequences of Trichosporon colonization appear to be extremely rare. Treatment of Trichosporon should be withheld until a second culture reveals persistence of $T$. inkin in a symptomatic patient in whom no other cause of symptoms is identified. Based on in-vitro susceptibility, clinical eradication of T. inkin should follow treatment with topical or oral azoles.

\section{REFERENCES}

1. Itoh T, Hosokawa H, Kohdera U, et al. Disseminated infection with Trichosporon asahii. Mycoses 1996;39:195-9

2. Gueho E, Smith MTH, deHoog GS, et al. Contributions to a revision of the genus Trichosporon. Antonie Van Leeuwenhoek 1992;61:289-316

3. Gueho E, Improvisi L, deHoog GS, et al. Trichosporon on humans: a practical account. Mycoses 1994;37:3-10

4. Therizol-Ferly M, Kombila M, Gomez de Diaz M, et al. Piedra and Trichosporon species in equatorial Africa. Mycoses 1994;37:249-53

5. Mayser P, Huppertz M, Papavassilis $\mathrm{CH}$, et al. Yeasts of the genus Trichosporon. Identification, epidemiology and significance in dermatological disease. Hautarzt 1996;47:913-20

6. Chaumentin G, Boibeux A, Piens MA, et al. Trichosporon inkin endocarditis; short-term evolution and clinical report. Clin Infect Dis 1996; 23:396-7

7. Lopes JO, Alves SH, Klock C, et al. Trichosporon inkin peritonitis during continuous ambulatory peritoneal dialysis with bibliography review. Mycopathologia 1997;139:15-18

RECEIVED 09/16/02; ACCEPTED 03/17/03
8. Piwoz JA, Stadtmauer GJ, Bottone EJ, et al. Trichosporon inkin lung abscesses presenting as a penetrating chest mass. Pediatr Infect Dis J 2000;19:1025-7

9. National Committee for Clinical Laboratory Standards. Development of In Vitro Susceptibility Testing Criteria and Quality Control Parameters. Approved Guidelines for M27-A. Villanova, PA; National Committee for Laboratory Standards, 1994

10. Odds FC. Candidosis of the genitalia. In Candida and Candidiasis. A Review and Bibliography, 2nd edn. Philadelphia, PA: Bailliere Tindall 1998:124-36

11. Sobel JD. Epidemiology and pathogenesis of recurrent vulvovaginal candidiasis. Am J Obstet Gynecol 1985;152:924-35

12. Sobel J, Vazquez J, Lynch M, et al. Vaginitis due to Saccharomyces cervisiae. Epidemiology, clinical aspects and therapy. Clin Infect Dis 1993;16:93-9

13. Sobel JD. Vaginal mucomycosis: a case report. Infect Dis Obstet Gynecol 2001;9:117-18

14. Ebright JR, Fairfax MR, Vazquez JA. Trichosporon asahii, a non-Candida yeast that caused fatal septic shock in a patient without cancer or neutropenia. Clin Infect Dis 2001;33:28-30 


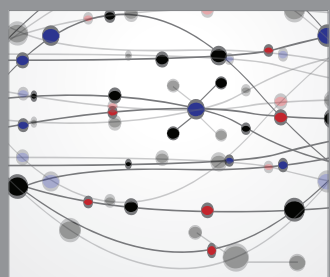

The Scientific World Journal
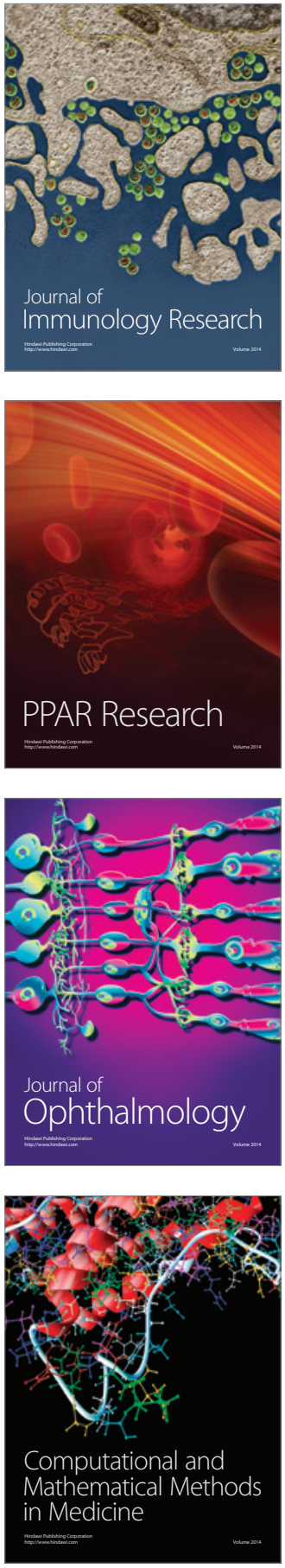

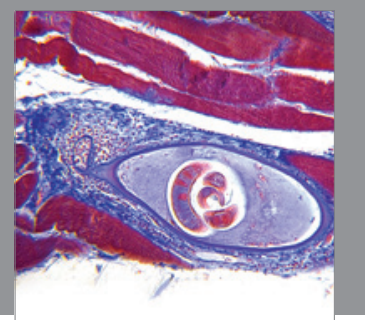

Gastroenterology

Research and Practice
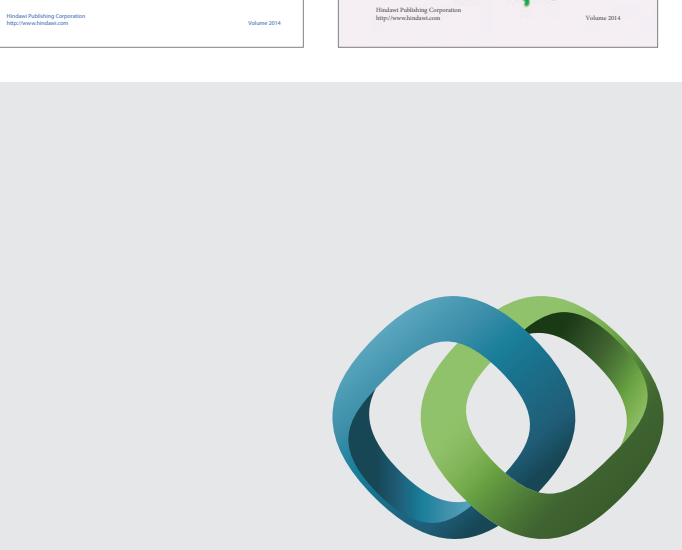

\section{Hindawi}

Submit your manuscripts at

http://www.hindawi.com
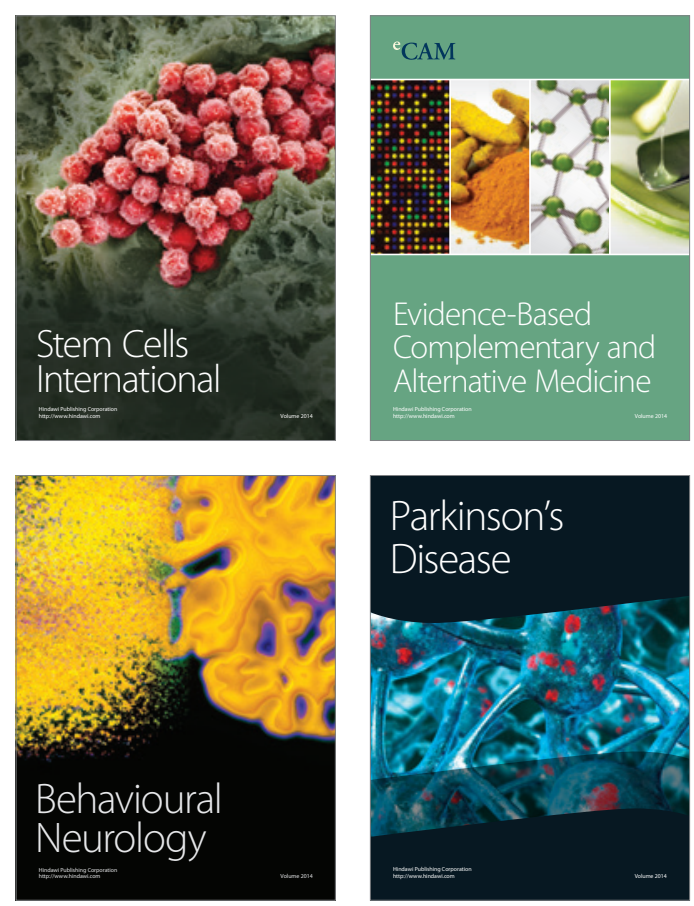

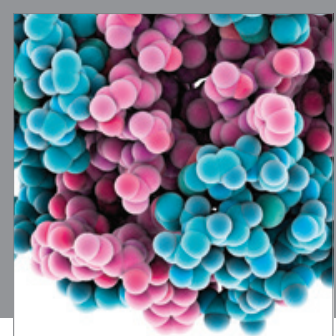

Journal of
Diabetes Research

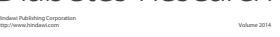

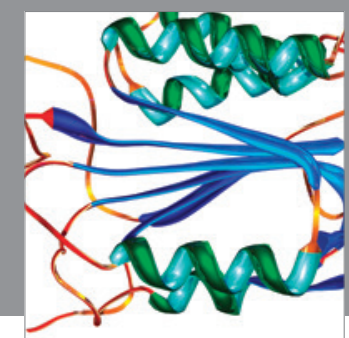

Disease Markers
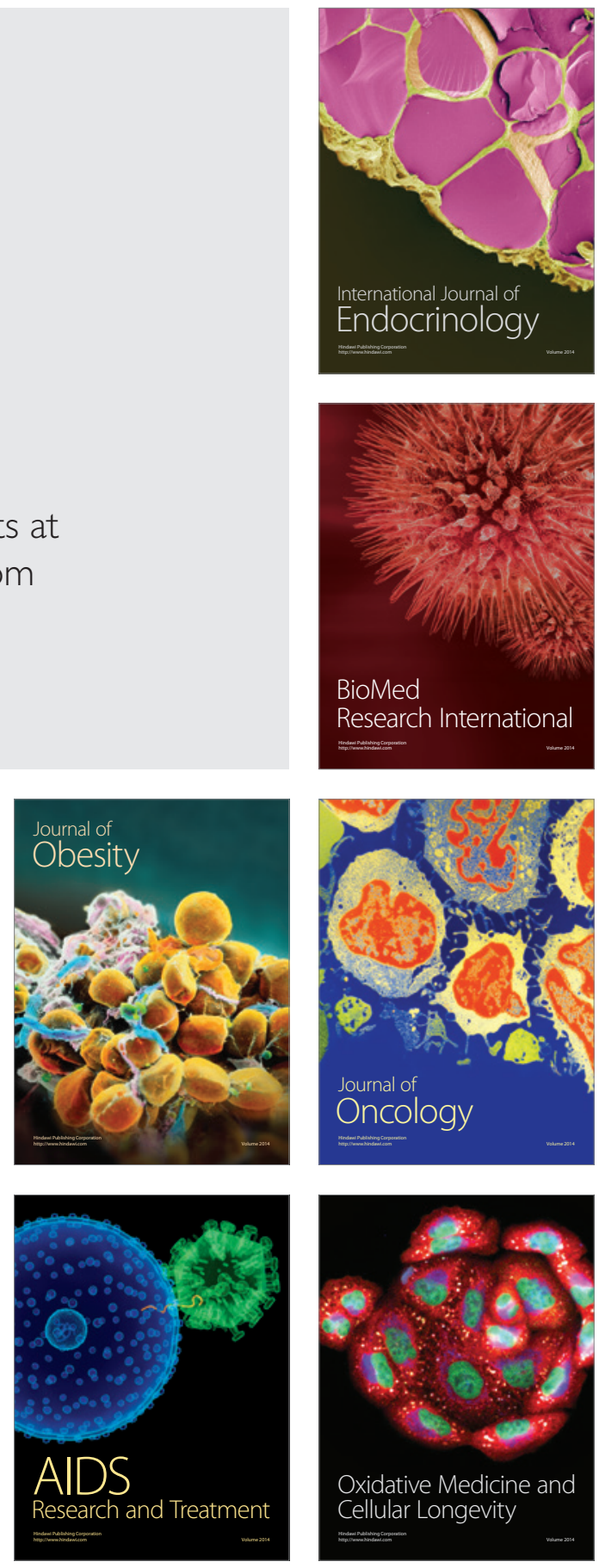